Hennigen, I.; Guareschi, N.M.F. "A paternidade na contemporaneidade: um estudo de mídia sob a perspectiva dos estudos culturais"

\title{
APATERNIDADE NA CONTEMPORANEIDADE: UM ESTUDO DE MÍDIA SOB A PERSPECTIVA DOS ESTUDOS CULTURAIS
}

\author{
Inês Hennigen \\ Universidade de Caxias do Sul \\ Neuza Maria de Fátima Guareschi \\ Pontifícia Universidade Católica do Rio Grande do Sul
}

RESUMO: Neste artigo discutimos as possibilidades que a perspectiva dos Estudos Culturais abre para a pesquisa em Psicologia Social e, de forma mais específica, para a temática da paternidade. Questões relativas à construção das identidades e à importância da mídia neste processo são discutidas. A paternidade é aqui concebida como uma construção social que acompanha o caráter flexível das demais posições identitárias. A análise de um comercial de televisão é apresentada e mostra como diferentes aspectos da cultura contemporânea se atravessam e mesclam com a temática pai.

PALAVRAS-CHAVES: identidades, paternidade, mídia, Estudos Culturais.

THE MEANINGS OF FATHERHOOD IN THE MEDIA: A CULTURAL STUDIES PERSPECTIVE

ABSTRACT: In this article, we discuss the possibilities that the perspective of Cultural Studies open for the research in Social Psychology, more specifically, for the paternity's thematic. Questions related to the identities construction and the media importance in this process are discussed. Paternity here is conceived as a social construction that follows the flexible character of other identity positions. The analysis of a television advertising is presented and shows how different aspects of the contemporary culture cross over and mix with the father's thematic.

KEY WORDS: identities, paternity, media, Cultural Studies 
Psicologia \& Sociedade; 14 (1): 44-68; jan./jun.2002

\section{INTRODUÇÃO}

A paternidade afigura-se como a temática particular deste artigo; antes de abordá-la, pensamos ser pertinente situar o lugar de onde falamos, nossos questionamentos, as opções e caminhos que trilhamos na aproximação desse objeto de pesquisa.

Inicialmente discutimos o que nos parece ser uma certa circularidade das diferentes psicologias sobre seus próprios referenciais e práticas, estado que dificulta a abertura tanto aos conhecimentos gerados no seu próprio âmbito, quanto aos produzidos por outras disciplinas. Pesquisadoras da psicologia social, encontramos no campo dos Estudos Culturais inspiração para nosso trabalho, visto ser esta perspectiva - sobre a qual apresentamos um pequeno histórico - intrinsecamente interdisciplinar e preocupada com temáticas relativas à identidade, o que consideramos básico para alicerçar o estudo da paternidade.

Assim, na sequiência do artigo, as problematizações sobre as identidades no mundo contemporâneo, concebidas como plurais e processuais, são discutidas. Mostramos que, atualmente, as múltiplas interpelações pelos sistemas culturais nos desautorizam a falar de um centro interior do qual emerge a identidade: ao contrário, as identidades se formam e transformam na tensão entre os discursos da cultura e o desejo de assumir seus significados ${ }^{1}$. Como outras posições identitárias - por exemplo, ser mulher, ser negro -, pensamos que ser pai (tanto suas significações como o próprio vivenciar a paternidade) também é uma construção contínua, plural e sempre em aberto, que se processa nesta tensão cultura/indivíduo.

O Feminismo, ao questionar as posições femininas e masculinas e as relações de gênero, contribuiu para desestabilizar a representação 'tradicional' da masculinidade e da paternidade, possibilitando a circulação de novas significações e incentivando a busca de novas compreensões sobre a constituição subjetiva. Em função disto, consideramos fundamental discutir neste trabalho algumas contribuições do discurso feminista e dos estudos de gênero.

Da mesma forma, como acreditamos que as produções culturais nos subjetivam, optamos por buscar conhecer as formas como a mídia representa o pai, a paternidade. A mídia tem sido considerada um lugar privilegiado de circulação de discursos em nossa sociedade, logo, importante para as construções identitárias. Assim, além de abordar algumas discussões sobre os produtos midiáticos, seus discursos plurais e a apropriação que se faz dos mesmos, apresentamos os raros trabalhos que focam pater- 
Hennigen, I.; Guareschi, N.M.F. "A paternidade na contemporaneidade: um estudo de mídia sob a perspectiva dos estudos culturais"

nidade e mídia.

De um universo de 16 comerciais veiculados na RBSTV de Porto Alegre na época do Dia dos Pais de $2000^{2}$, escolhemos um comercial para analisar; nessa análise consideramos conteúdos e estratégias de produção pois entendemos um vínculo indissociável entre ambos. Da mesma forma, não nos detivemos somente nas mensagens hegemônicas, mas buscamos contemplar o alternativo, pois pensamos que espectadores e espectadoras, no processo de recepção, fazem suas próprias articulações a partir da totalidade de um produto midiático, posição que rompe com a concepção de mídia como instrumento de dominação.

Ainda a título de introdução, é importante tecer alguns comentários acerca dos objetivos deste trabalho. Uma temática como paternidade pode ser abordada sob variados prismas - o que desejamos, antes de mais nada, é explorar uma destas possibilidades. Com um olhar crítico a respeito das produções no campo da psicologia social, buscamos subsídios junto ao campo dos Estudos Culturais para ir compondo um novo caminho.

Este artigo apresenta, ao mesmo tempo, a discussão de algumas costuras teóricas realizadas e a exploração das possíveis articulações entre teoria e material empírico. Ao contrário de propor um foco de análise específico, visamos, no presente trabalho, explorar linhas de pensamento que se mostraram promissoras para o estudo de nossa temática de interesse.

Por considerarmos que todas as identidades são construídas culturalmente, alinhamos paternidade e mídia na busca de alguns aspectos que estão sendo relacionados à representação da paternidade na publicidade televisiva. Pensamos que esta estratégia abriu espaço para, conhecendo alguns significados atribuídos ao pai, buscar compreender as diversas faces da paternidade em nossa cultura, os discursos que se conjugam na sua constituição.

\section{PSICOLOGIA SOCIALE ESTUDOS CULTURAIS: UM ENCONTRO PRODUTIVO}

A Psicologia, mais particularmente a Psicologia Social, necessita estar conectada ao contemporâneo para responder de modo mais efetivo às grandes questões que atravessam nossa sociedade. Para isso não basta aos psicólogos e psicólogas apenas se debruçar em temáticas da atualidade. É fundamental que busquem novas perspectivas, novas formas de olhar, enfim, alternativas teórico-metodológicas que possam acolher a comple- 
xidade do mundo contemporâneo.

Para quem se encontra fora de nosso campo, isto pode parecer não problemático, visto que a Psicologia se caracteriza pela pluralidade teórica e prática. Contudo, como muito bem pontua Moreira (1997, p.9), padecemos, freqüentemente, do "... sintoma da incomunicabilidade de posições que se fecham e alienam em seus guetos". Algumas temáticas e insights teóricos parecem ser de domínio de certas linhas de pensamento ou das áreas de conhecimento em que se dividiu o espaço psicológico, cujas fronteiras são pouco permeáveis: o novo, diferente, é, muitas vezes, rechaçado por não fazer parte da tradição. Assim, as psicologias se fecham sobre si mesmas e, muitas vezes, também são refratárias aos conhecimentos produzidos em outros campos.

Luís Cláudio Figueiredo, psicanalista e pesquisador da Psicologia $^{3}$, traça considerações recheadas de ironia e muito perspicazes sobre esta questão. Afirma que, para a Psicologia alcançar a maioridade, é necessário enfrentar tradições para conquistar o direito de um livre pensar, que implica pensar a partir da própria experiência e confrontar-se com outros pensamentos, antagônicos ou convergentes. Neste sentido, propõe “... a idéia de que deveríamos caminhar na direção de uma psicologia vira-lata" (1999, p.5).

Ao contrário do filhote de raça pura - valorizado quando reproduz o padrão da raça, sendo frágil e dependente de certas condições para sobreviver -, o vira-lata é resultado de misturas que deram certo, tem um estilo bem próprio, se cria e aprende face às necessidades e possibilidades. Sobre as vias para alcançar esta postura de vira-lata, Figueiredo (1999, p. 5) questiona se: “ ... falar em 'fórmulas' e 'formação' já nos estará aprisionando nos canis - campos de concentração canina - em que se criam psicólogos com pedigree. Tão bonitinhos, tão frágeis de saúde (mesmo quando ferozes e agressivos), tão inúteis" ${ }^{\prime}$.

A possibilidade de 'misturas', de variadas articulações teóricas e metodológicas que vão se fazendo face às necessidades reveladas pelas questões de uma pesquisa é, em síntese, a proposta do campo dos Estudos Culturais, cujo objetivo é produzir conhecimentos que sejam úteis (Johnson, 2000). Assim, a recente abertura da Psicologia Social a esta perspectiva representa um novo fôlego para quem se interessa em compreender questões relativas à subjetividade e às identidades no mundo contemporâneo ${ }^{5}$.

Os Estudos Culturais têm uma origem britânica e, nas últimas décadas, vêm se desenvolvendo em vários países, adquirindo feições próprias em cada contexto. A interdisciplinaridade é uma característica central 
Hennigen, I.; Guareschi, N.M.F. "A paternidade na contemporaneidade: um estudo de mídia sob a perspectiva dos estudos culturais"

deste campo, que estuda os aspectos culturais da sociedade contemporânea a partir da interseção de diversas disciplinas. Acolhe, seletivamente, insights teóricos do marxismo e neomarxismo, teorias feministas, estruturalismo e pós-estruturalismo, psicanálise e pós-modernismo, numa espécie de alquimia para produzir conhecimento ${ }^{6}$.

A conexão entre trabalho intelectual e político marca os Estudos Culturais, seja pela não subordinação aos limites disciplinares, pelo vínculo com os diversos movimentos sociais ou por propor que a cultura, antes de dizer respeito aos domínios estético ou humanístico, está ligada ao domínio político (Costa, 2000). Assim, seu compromisso é “... examinar práticas culturais do ponto de vista de seu envolvimento com, e no interior de, relações de poder" (Nelson, Treichler e Grossberg, 1998, p. 11). A cultura seria, então, um locus onde se estabelecem divisões que implicam em desigualdades, onde acontecem os embates políticos: o espaço privilegiado em que ocorre a luta pela significação.

Os primeiros trabalhos neste campo enfocavam produtos da cultura popular e meios de comunicação de massa; posteriormente, a questão da identidade, entre uma variedade de temáticas, também passa a ser estudada. A partir dos anos 80, sob influência de teóricos como Bourdieu e Foucault, os estudos já não contemplavam como antes as categorias de luta e resistência, o que, para alguns analistas, representou o início da despolitização dos Estudos Culturais. Contudo, o que é visto como restritivo por uns, pode significar o inverso para outros. "A desconstrução e o movimento de afastamento das oposições binárias, incluindo a dos inícios e dos finais absolutos, podem ser vistos aqui como uma abertura para uma nova forma de conceptualizar o campo político e criar um novo conjunto de métodos ..." (McRobbie, 1998, p.42).

Acreditamos que um trabalho realizado sob esta perspectiva traz em seu bojo a flexibilidade e a crítica, tão necessárias para se pensar a contemporaneidade: a pesquisa passa a ter 'movimento'. Assim, em nosso estudo sobre paternidade alguns encontros teóricos foram acontecendo. $\mathrm{O}$ primeiro, discutido no próximo tópico, nos remeteu à questão das identidades.

\section{NOVAS PERSPECTIVAS SOBRE IDENTIDADE}

As complexas mudanças que estão ocorrendo no mundo contemporâneo - as rupturas no projeto da Modernidade (Veiga-Neto, 2000) - têm sido discutidas por inúmeros pensadores que, em geral, colocam em des- 
taque a fragmentação da subjetividade, recorrendo a mecanismos sociais diferenciados para entender sua ocorrência (Fridman, 2000).

Para Hall (1998), as estruturas e os processos centrais das sociedades modernas estão sofrendo alterações que abalam seus quadros de referência. A concepção de uma identidade unificada que estabilizava o mundo social ruiu; as paisagens culturais de classe, gênero, sexualidade, etnia, raça e nacionalidade estão fragmentadas; o indivíduo perdeu suas localizações sociais e o sentido de si, numa espécie de dupla descentração. "No nosso tempo, a insegurança, o medo e a fragilidade dos laços contraídos pelos indivíduos entre si atestam as dificuldades de construção da identidade em um mundo marcado pela pluralidade e por alterações significativas na institucionalidade" (Fridman, 2000, p. 63).

No pensamento pós-moderno, o self é necessariamente incompleto, inacabado; o que vigora é o sujeito em processo (Sarup, 1996). O sujeito pós-moderno não tem mais uma identidade essencial, mas várias identidades (trans)formadas continuamente em relação ao modo como é representado ou interpelado pelos sistemas culturais ao redor, podendo ser contraditórias ou não-resolvidas. Assim, “.... à medida em que os sistemas de significação e representação cultural se multiplicam, somos confrontados por uma multiplicidade desconcertante e cambiante de identidades possíveis, com cada uma das quais poderíamos nos identificar - ao menos temporariamente" (Hall, 1998, p.13).

Apesar do indivíduo estar exposto a variadas situações de interpelação, para ele se identificar, ser interpelado por um significado específico - e, por extensão, com o sistema de significação do qual este faz parte deve ser "... capaz de dar, para si mesmo, um sentido ao(s) enunciado(s) que escora (m) tal significado ..." (Veiga-Neto, 2000, p. 58). As divisões sociais e antagonismos característicos das sociedades contemporâneas produzem uma variedade de posições de sujeito: sob certas circunstâncias, os diferentes elementos podem ser articulados conjuntamente, mas isto é sempre parcial e a estrutura da identidade continua aberta (Laclau e Mouffe apud Sarup, 1996).

O dinamismo é a tônica: caso um enunciado volte a nos interpelar, pode nos encontrar noutra posição e o resultado será diferente. É importante ressaltar que aceitar uma 'verdade' não remete só ao racional: ou ela é imposta violentamente (e aí se pode resistir) ou "... nos deixamos capturar por ela, como um efeito do poder, o qual, sendo sutil e insidioso, nos impõe tal verdade como natural e, portanto, necessária" (Veiga-Neto, 2000, p.58). 
Hennigen, I.; Guareschi, N.M.F. "A paternidade na contemporaneidade: um estudo de mídia sob a perspectiva dos estudos culturais"

Os Estudos Culturais têm, nos últimos anos, direcionado seu interesse às questões da subjetividade e identidade e para os textos culturais e midiáticos que se dirigem ao domínio privado e doméstico (Escosteguy, 2000). Segundo Veiga-Neto (2000, p. 53), “... os Estudos Culturais já estabeleceram sólidos avanços na compreensão dos novos jogos de poder pelos quais se estabelecem identidades, significados sociais e culturais e pelos quais estamos, ao que tudo indica, sendo cada vez mais governados".

A cultura tem, na contemporaneidade, papel constitutivo de todos os aspectos da vida social. Os seres humanos utilizam sistemas ou códigos de significado para interpretar, organizar e regular sua conduta, enfim, para dar sentido às próprias ações assim como às ações dos outros: são suas culturas. Assim, uma vez que todas as práticas sociais comunicam significado, constituem-se como práticas de significação (Hall, 1997).

A centralidade da cultura, em sua dimensão global, tem interessado pensadores de todas as áreas do conhecimento - da Filosofia à Economia - por sua relevância no que diz respeito à estrutura e organização da sociedade: as chamadas indústrias culturais são, ao mesmo tempo, infraestrutura material e meio de circulação de idéias e imagens. Contudo, Hall (1997) alerta que o nível macro não pode eclipsar o fato de que esta revolução cultural tem uma incidência importantíssima na vida cotidiana das pessoas comuns.

O encontro, através dos sistemas de comunicação, com histórias sociais distintas e com diferentes modos de vida causa impacto sobre o sentido que as pessoas dão a sua vida e a seus projetos. Para além das discussões sobre tendências e resistências à homogeneização cultural, não se pode negar que os padrões e tradições do passado estão menos nítidos. Um rápido panorama sobre trabalho e família permite constatar alterações significativas: a flexibilização do emprego pode levar ao temido desemprego ou, pelo menos, a questionamentos sobre as perspectivas numa carreira; a diversidade de arranjos familiares implica a invenção de novos estilos de relações entre parceiros e com filhos/as.

Hall (1997) utiliza a expressão centralidade da cultura para mostrar sua incidência em cada recanto da vida social, sendo um elemento chave na ligação entre ambiente doméstico e tendências mundiais. Neste sentido, está convicto de que a cultura "não pode mais ser estudada como uma variável sem importância, secundária ou dependente em relação ao que faz o mundo mover-se; tem de ser vista como algo fundamental, constitutivo, determinando tanto a forma como o caráter deste movimento, bem como a sua vida interior" (p.23). 
Psicologia \& Sociedade; 14 (1): 44-68; jan./jun.2002

Johnson (2000) afirma que todas as práticas sociais podem ser examinadas pelo trabalho que elas fazem subjetivamente. Esta perspectiva choca-se com a antiga (será?) distinção entre a esfera do social e do psíquico: as questões da cultura estão enfraquecendo a linha divisória entre a Sociologia e a Psicologia. Assim, Hall (1997) enfatiza que não se pode pensar mais que a identidade emerge de um centro interior, mas sim da tensão entre os discursos da cultura e o desejo (consciente ou inconsciente) de responder aos seus significados e identificar-se. Sarup (1996) afirma que todas as identidades - de classe, gênero, étnicas - são construções sociais e entende que é fundamental colocar a questão da identidade no contexto da história, linguagem e poder, o que remete ao caráter discursivo das práticas sociais.

Com o objetivo de esclarecer as críticas sobre um suposto 'idealismo cultural', tão reducionista quanto qualquer outro, Hall (1997, p. 33) diz que “... toda prática social tem condições culturais ou discursivas de existência. As práticas sociais, na medida em que dependem do significado para funcionarem e produzirem efeitos, se situam 'dentro do discurso', são 'discursivas"”.

A noção de discurso, desenvolvida na Lingüística, tem contribuído de forma significativa em diversos campos do conhecimento, mas sua 'importação' nem sempre é isenta de problemas: algumas vezes é simplificada e perde sua especificidade, noutras requer a reorganização do quadro conceptual do campo para viabilizar novas articulações (Pinto, 1989). Segundo Hall (1997, p.29), "o termo refere-se tanto à produção de conhecimento através da linguagem e da representação, quanto ao modo como o conhecimento é institucionalizado, modelando práticas sociais e pondo novas práticas em funcionamento".

Pinto (1989) apoia-se no pensamento de Barthes para enfatizar a historicidade da construção social de significado: os sujeitos e os discursos são construídos a partir das significações tomadas como sendo o sentido natural das coisas num dado momento histórico. Assim, os sujeitos sociais não são causa do discurso, são efeitos discursivos. Esta autora, que não descarta a existência de um discurso dominante, afirma que esse não constitui uma racionalidade que dá sentido a todas as relações sociais. Enfatiza a multiplicidade de discursos - de lógicas - no interior da sociedade, o que enfraquece a posição de poder de cada discurso em particular e acarreta uma constante luta entre os mesmo no sentido de interpelar novos sujeitos. 
Hennigen, I.; Guareschi, N.M.F. "A paternidade na contemporaneidade: um estudo de mídia sob a perspectiva dos estudos culturais"

\section{APATERNIDADE COMO CONSTRUÇÃO SOCIAL}

Os analistas da contemporaneidade têm mostrado a fragilidade dos laços entre os indivíduos, a transitoriedade das posições identitárias e as profundas mudanças ocorridas nas instituições sociais. Como pensar as posições paterna e materna neste cenário? Indicadores demográficos revelam a crescente diversidade dos arranjos familiares, mas estes dados, tomados isoladamente, não ajudam a entender como estão se constituindo os lugares sociais de pai, mãe, filhos/as; demonstram, sim, a pluralização das relações familiares. Portanto, há que se buscar a forma como estão sendo significadas/vivenciadas.

Ser pai era considerado, até pouco tempo, algo da ordem do natural e a ciência, assim como a crença popular, afirmava a importância do pai para o desenvolvimento da criança; em função dessa naturalização, estudos mais aprofundados a respeito da relação pai-filhos/as e sobre os caminhos da paternidade para o homem não eram empreendidos. A rápida ascensão do número de separações/divórcios e o afastamento do pai - não necessário, mas constatado na prática - inaugurou uma vertente de pesquisas que passou a investigar as conseqüências da sua ausência (Silveira, 1998). Entretanto, só a partir dos estudos sobre a mulher, impulsionados pelo feminismo, que pesquisadores/as vão buscar compreender melhor a masculinidade e a paternidade, que passam a ser vistas sob outro prisma, como construções sociais.

As mudanças sócio-econômicas e culturais que foram se consolidando na segunda metade do século XX provocaram alterações nas condições femininas e masculinas, desencadeando a necessidade de se buscar diferentes compreensões sobre as relações pessoais e sobre os laços e novas configurações familiares. Neste contexto, o Feminismo, que inicia como um movimento de reivindicação de igualdade de direitos sociais, abre espaço para investigações em diversas áreas.

Como aponta Hall (1998), o Feminismo, junto a outros movimentos sociais dos anos 60 , foram fundamentais para deslocar a concepção de sujeito moderno. Contribuíram de forma direta com questionamentos sobre dicotomias, como privado-público; com a abertura de novas arenas de discussão política, esferas intocadas da vida social como a família, a divisão doméstica do trabalho e o cuidado com as crianças; e, principalmente, com a politização da subjetividade e do processo de identificação.

A partir da compreensão, no âmbito dos estudos feministas, de que estudar a condição da mulher implica, necessariamente, remeter-se à 
Psicologia \& Sociedade; 14 (1): 44-68; jan./jun.2002

condição do homem, estes estudos evoluíram no sentido de abordar as relações de gênero. Assim, cria-se uma nova perspectiva, que contempla a questão do poder: “... a de conceituar gênero como categoria analítica, que permitiria compreender ou interpretar uma dinâmica social que hierarquiza as relações entre o masculino e o feminino" (Arilha, Medrado e Ridenti, 1998, p.24).

No âmbito internacional, as pesquisas sobre masculinidade remontam à década de 70, mas são eclipsadas pelos estudos sobre mulheres. $\mathrm{Na}$ década seguinte, aparecem, com maior consistência, estudos sobre a construção social da masculinidade, diretamente beneficiados pelas reflexões em torno do conceito de gênero. Estudos sobre a paternidade surgem como um campo particular e investigam a participação mais efetiva do homem no cotidiano familiar, mais especificamente no cuidado com filhos/as: este homem passa a ser caracterizado como o novo pai. Pesquisadores/as brasileiros/as afirmam que o interesse pelo tema vem crescendo, mas ainda de forma fragmentada (Arilha, Medrado e Ridenti, 1998).

Refletindo sobre os avanços nos estudos de gênero, Garcia (1998) aponta que os estudos sobre masculinidades estão enfatizando a diversidade de modelos masculinos advinda da pluralidade de suas vivências. "Há uma diversidade de tipos de masculinidades, que correspondem a diferentes inserções dos homens na estrutura social, política, econômica e cultural...” (p. 36). A autora acredita que, para o progresso do debate sobre masculinidades, há necessidade de se trabalhar a complexa interação entre gênero e outras dimensões sociais como raça, etnia, orientação sexual, grupos sócio-econômicos e geracionais.

Nesse sentido, é pertinente comentar o estudo de Trindade, Andrade e Souza (1997) que revela diferenças nas representações sociais da paternidade de homens de duas gerações: pais da década de 80, principalmente os de nível de escolaridade superior, enfatizam os aspectos afetivos da relação pai-filho/a; já a categoria provedor é mais referida pelos pais dos anos 60. Com base no que os Estudos Culturais já mostraram - que as posições que cada sujeito assume, com as quais se identifica, são atravessadas por ' $\mathrm{n}$ ' discursos e possibilidades presentes em um certo tempo - o insight de que gênero é somente uma categoria é realmente bastante importante.

Atualmente, o que os homens estão experienciando em relação à paternidade? Konrath (1996) investiga as concepções de homens sobre o que é ser pai, como deve ser um pai e constata que eles querem ter diálogo e intimidade, mas preocupam-se com sua responsabilidade diante dos/as 
Hennigen, I.; Guareschi, N.M.F. "A paternidade na contemporaneidade: um estudo de mídia sob a perspectiva dos estudos culturais"

filhos/as; criticam o estilo de seu pai, mas muitas vezes se sentem desconfortáveis quando assumem outra posição. A busca de uma posição diferente frente aos/às filhos/as também é revelada pelos homens entrevistados por Saraiva (1998), que enfatiza a necessidade de uma reconstrução da posição dos homens/pais para que eles possam assumir a própria masculinidade exercendo uma paternagem conectada com afetos e prazeres. A tônica na fala destes homens recai sobre a participação, que define novas atitudes no cuidado e na relação com filhos/as e não está, como poderia se pensar, atrelada à convivência cotidiana.

Ramires (1997), que investiga como o pai participa e vivencia subjetivamente a relação com os/as filhos/as, também verifica o desejo de participação. A referência ao monopólio materno, gerador de tensão, é bastante freqüente, assim como à capacidade de 'maternar' do pai. Respaldada pelos estudos de gênero, a autora compreende a hipótese da competência exclusiva da mulher para a maternagem como conseqüência da educação sexista. Assim, propõe que um novo modelo de relação, não hierárquico, excludente e de poder, talvez possa ser possível se os cuidados infantis forem compartilhados por pai e mãe desde o início. Contudo, pensa não ser o bastante: há necessidade de mudanças nas estruturas sociais, políticas, econômicas e, o que considera indissociável, nas mentalidades.

Para um grupo de pesquisadores americanos (Cabrera, TamisLeMonda, Bradley, Hofferth e Lamb, 2000), o significado da paternidade e o envolvimento efetivo com os/as filhos/as relaciona-se à identidade de gênero e às experiências dos homens com seus próprios pais e parentes. Contudo, afirmam que há uma diversidade muito grande por conta das variações culturais e étnicas e que não existe uma definição simples de paternidade de sucesso, que possa reivindicar aceitação universal. Ao contrário, eles propõem que expectativas paternas, práticas realizadas e seus efeitos sobre as crianças precisam ser vistos dentro do contexto da família, comunidade, cultura e história.

\section{A MÍDIA E A CONSTRUÇÃO DAS POSIÇÕES DE PAI}

Neste ponto, cabe centrar a discussão na construção das posições de pai. Pensamos, como Saraiva (1998), que a paternidade é uma experiência humana profundamente implicada com propósitos sociais e institucionais que a legitima, ou seja, uma construção que deve ser compreendida face ao contexto sócio-cultural de um tempo.

Como as identidades são construídas culturalmente, a mídia des- 
Psicologia \& Sociedade; 14 (1): 44-68; jan./jun.2002

ponta, em nosso tempo, como um lugar privilegiado de circulação de discursos, tornando-se fonte de referências identitárias. "A mídia é uma dessas instâncias sociais que produz cultura, veicula e constrói significados e representações" (Sabat, 1999, p.245). Conforme Fischer (1999), em função da centralidade da cultura, não se pode mais conceber a construção de identidades sociais e individuais como uma questão só pertinente ao campo psicológico.

Fischer (2000) pensa que a mídia, por sua presença maciça em nossa vida, é mais que um veículo de exposição de modos de vida, funciona como um lugar decisivo no processo de construção de identidades. A autora vai além e diz que os discursos sobre os modos de ser e estar no mundo se produzem e reproduzem "... nos diferentes campos de saber e práticas sociais, mas passam a existir 'realmente' desde o momento em que acontecem no espaço dos meios de comunicação" (p.111).

O caráter pedagógico da mídia tem sido explicitado por pesquisadoras interessadas na formação dos sujeitos sociais. Para Sabat (1999), as imagens produzem uma pedagogia, ensinam sobre as coisas do mundo, produzem conceitos sobre o social, indicam formas de pensar e agir, de como se relacionar com o mundo, numa espécie de currículo cultural. Já Fischer (2001) busca caracterizar o "dispositivo pedagógico da mídia" a partir de uma série de categorias agrupadas em dois conjuntos: tecnologias do eu (formas como se produz a reflexão sobre si mesmo, em especial sobre o corpo e sobre os modos de ser) e estratégias de linguagem televisiva (relativo a um tipo de sintaxe da mídia que se harmoniza com suas práticas de subjetivação). Para a autora, considerar os diferentes recursos de linguagem utilizados nas produções midiáticas possibilitaria “.... ultrapassar aquelas análises muitas vezes meramente ideológicas, pelas quais nos aventuramos a buscar 'o que está por trás' das enunciações, como se estas escondessem certos enunciados, ao invés justamente de evidenciá-los” (p.16).

Os discursos que a mídia faz circular, apesar de múltipla origem, as vezes de difícil localização, são tomados de empréstimo da cultura vivida pelas pessoas (Johnson, 2000). Como afirma Pinto (1989), o sujeito retratado nas produções publicitárias é uma ficção literária: é no interior dos discursos presentes na sociedade que a publicidade busca lugar para significar o que quer vender. "Suas imagens trazem sempre signos, significantes e significados que nos são familiares" (Sabat, 1999, p.250).

Os textos culturais são complexos, múltiplos, sobrepostos, coexistentes, em suma, intertextuais. As leituras são interdiscursivas: não há forma subjetiva que atua por conta própria. As combinações não podem 
Hennigen, I.; Guareschi, N.M.F. "A paternidade na contemporaneidade: um estudo de mídia sob a perspectiva dos estudos culturais"

ser preditas por meios formais ou lógicos, ao contrário, advém de lógicas particulares dos leitores, como suas localizações sociais, suas histórias, seus mundos privados (Johnson, 2000).

Neste sentido, Fischer (1999) aponta a disputa pela imposição de determinados sentidos: mesmo que estejamos submetidos a uma lógica publicitária de existir, esta não é fechada pois nos meios de comunicação e mais particularmente na publicidade - estão em jogo diferentes valores, idéias, identidades, conquistas sociais e também “...porque nenhum de nós se submete igualmente e com a mesma intensidade a todo e qualquer discurso" (p. 25).

Que discursos a mídia está produzindo sobre/para os pais? Podese dizer que a forma como o pai vem sendo retratado se alterou profundamente nas últimas décadas: basta comparar o pai da série Papai sabe tudo, dos anos 50/60, e Hommer, o pai 'bobão' da série Os Simpsons, dos anos 90. Contudo são raros os estudos que buscam investigar o que está circulando sobre os homens no contexto familiar.

Medrado (1999), em sua pesquisa sobre o masculino na mídia, constata que os comerciais analisados apresentam um modelo cultural ideal de homem (branco, heterossexual e dominante), mas que, por meio de dispositivos humorísticos, começam a surgir tentativas de romper com os padrões tradicionais. Naquelas produções cuja temática é relativa ao cuidado infantil, Medrado (1998) encontra uma distinção dicotômica das atribuições parentais: cabe ao pai o provento material e moral e à mãe a dimensão afetiva, o cuidado das crianças. Na maioria dos comerciais dessa categoria, a mãe ocupa a posição de protagonista e, quando o pai é a figura central, sua ação é no sentido de educar moralmente ou garantir o futuro financeiro do/a filho/a. $\mathrm{O}$ autor também encontra referência ao que chama de pai pastelão (aquele que só atrapalha!); o afeto masculino conectado ao cuidado só aparece metaforicamente e relacionado a animais de estimação.

Kaufman (1999) revisou a literatura internacional sobre o papel familiar masculino nas produções televisivas e verificou que o homem é retratado de formas diversas em comerciais veiculados em diferentes momentos do dia e também naqueles realizados em diferentes países. Os resultados de sua própria pesquisa revelam coincidências com achados anteriores: homens aparecem mais fora de casa; quando estão na companhia de criança - meninos, em geral - há uma mulher/esposa na cena; a brincadeira, o jogo, é a forma de interação mais freqüente.

As produções televisivas analisadas por esse autor, contudo, tra- 
Psicologia \& Sociedade; 14 (1): 44-68; jan./jun.2002

zem algumas novidades, como maior envolvimento dos homens nas atividades de ler/ensinar as crianças, além de mostrar que a interação homem/ criança é bastante freqüente em comerciais de sobremesas, restaurantes fast food ou cujo foco são os produtos para o café da manhã. Para Kaufman (1999), é uma forma de se envolver sem necessidade um esforço mais efetivo. Assim, se por um lado uma maior interação está aparecendo, os produtos consumidos ou a forma como acontece a interação remetem a uma posição mais 'tradicional'.

\section{REFLEXÕES A PARTIR DO MATERIAL EMPÍRICO}

Na semana que antecedeu o Dia dos Pais em 2000, gravamos 16 diferentes comerciais com algum conteúdo relativo à data, veiculados na RBS-TV Porto Alegre no horário das $20 \mathrm{~h}$ às $22 \mathrm{~h}$. Deste material, selecionamos um comercial - o do Shopping Iguatemi - para realizar o presente estudo. Esta escolha foi pontual, pois o referido comercial possibilita a reflexão sobre o enlaçamento de um tema como a paternidade a diferentes aspectos da cultura contemporânea, além de viabilizar também considerações sobre os próprios produtos midiáticos.

O comercial é dividido em cenas que acontecem num mesmo ambiente; não há diálogos, somente ações e expressões faciais, o som de fundo é uma música cadenciada.

Cena 1: um homem (H1) caminha em direção a uma parede de azulejos (o ângulo de filmagem mostra só a parte superior do corpo); ele se inclina à frente, curva cabeça e ombros e depois retorna à posição ereta.

Cena 2: ao lado do H1 encontra-se um homem mais velho (H2) que lhe sorri, enquanto o primeiro ostenta uma expressão séria; o H2, sorrindo e balançando a cabeça em sinal de aprovação, olha em direção à linha da cintura de $\mathrm{H} 1$, que também dirige o olhar para o mesmo ponto; $\mathrm{H} 2$, sempre sorrindo, dá três tapinhas nas costas de H1, que se afasta um pouco da parede, olha para trás com uma expressão séria, retorna, olha em direção à linha da cintura de $\mathrm{H} 2 \mathrm{e}$ os dois sorriem um para o outro.

Cena 3: uma mulher (M1) encara H1 e lhe oferece um lenço de papel; sozinho em cena, ele olha para o lenço com expressão séria e, em seguida, olha em frente como acompanhando o afastamento da M1.

Cena 4: H1 e outra mulher (M2) sorriem intensamente um para o outro; H1 olha em direção à linha da cintura da M2 enquanto ela ajusta sua blusa nos ombros; H1, sozinho em cena, dá um suspiro de alívio.

Cena 5: uma mulher (M3) bem jovem, chupando um pirulito, olha 
Hennigen, I.; Guareschi, N.M.F. "A paternidade na contemporaneidade: um estudo de mídia sob a perspectiva dos estudos culturais"

em direção à linha da cintura de $\mathrm{H} 1$ e balança a cabeça em sinal de reprovação; H1 também balança a cabeça da mesma forma, como solicitando uma confirmação; M3 olha novamente, sacode o pirulito em sinal de reprovação e sai de cena com os olhos fechados e sorrindo, enquanto o H1 balança a cabeça de um lado para o outro.

Cena 6: o ângulo de filmagem se inverte, amplia e mostra $\mathrm{H} 1$ de frente ao trocador de um fraldário; H1 suspende uma criança com a fralda descartável presa só de um lado, que cai pelas suas pernas à medida em que ela é levantada; H1 sorri olhando a criança; ao mesmo tempo, de cada lado, se aproxima uma mulher; H1 volta-se sorrindo para a mulher da direita (M4), toda de branco, de óculos, com expressão séria, e quando esta esboça um sorriso, ele fecha os olhos e aperta os lábios, voltando-se para o outro lado; a mulher da esquerda (M5) se aproxima de boca aberta e esboça um sorriso de complacência, quando H1 se volta para ela; H1 dirige seu olhar para a fralda caída e encolhe os ombros. Na parte final do comercial, em off, é apresentada a mensagem: "Dia dos pais Iguatemi: como o Iguatemi, só o Iguatemi."

Pode-se dizer que o comercial 'brinca' com o/a espectador/a: é estruturado de tal forma que o final constitui uma revelação que surpreende e diverte. Diferentes estratégias de produção ${ }^{7}$ são utilizadas para obter tal resultado: ângulo de filmagem, ausência de diálogos ou narrativa verbal e efeito lapagem (que justapõe cenas quebrando a continuidade da ação). $\mathrm{Na}$ cena inicial, uma série de elementos possibilita a seguinte leitura: trata-se de um banheiro. Atribuir esse sentido é uma base para se significar as cenas posteriores e para o desfecho inesperado. Mesmo que o efeito surpresa seja superado após a primeira audiência, as coisas 'ditas' neste comercial suscitam reflexões.

Como afirma Fischer (1999, p. 26), “... a mídia realiza esse espetacular trabalho de mesclar sentidos, de sobrepor imagens, de produzir um mosaico de emoções e valores, de idéias e sentimentos". Assim, a análise/ leitura de um texto deve ser tão aberta quanto possível, indicando quadros de referência preferenciais e alternativos, mesmo que esses apareçam como fragmentos (Johnson, 2000).

Iniciamos a análise justamente por um aspecto que aparece de forma secundária: a busca que a mídia empreende em capturar o mundo privado das pessoas. No cotidiano da TV podemos constatar a mescla entre público e privado, mormente a publicização do privado (Fischer, 1997). A cultura da exposição da vida íntima é sustentada, por exemplo, por programas de entrevistas em que se deve falar abertamente de tudo e por reporta- 
Psicologia \& Sociedade; 14 (1): 44-68; jan./jun.2002

gens que exploram histórias 'reais' (em geral, bastante delicadas), mas também está presente em comerciais - talvez de modo mais encoberto como neste - que contribuem igualmente para sustentar tal marca cultural.

Nesse comercial, a exposição do íntimo aparece de uma forma indireta. Uma câmera que capta imagens de personagens que estão de costas num suposto banheiro não estaria 'espiando' sua intimidade? Um homem que olha para trás antes de manifestar uma reação não dá um caráter privado ao que está acontecendo? Por outro lado, "o corpo é o grande alvo, pois ele se tornou o lugar por excelência de nossa identidade pessoal" (Fischer, 2000, p. 116).

Ao final do comercial se sabe que os personagens estão olhando e se referindo a um bebê, mas o fato dele não ser mostrado desde o início provavelmente foi pensado para produzir outra impressão. Os olhares para a linha da cintura remetem "...ao grande segredo sobre o qual não podemos jamais deixar de falar: o sexo" (Fischer, 2000, p.117). Aqui se brinca com esta dimensão de segredo: se 'fala' sobre sexualidade, mesmo não se tratando efetivamente disto. De alguma forma, na mídia, a referência ao sexual parece permear todas as esferas da vida dos indivíduos.

Consideramos pertinente abrir um parênteses aqui e acrescentar uma informação correlata que contribuirá para respaldar tal afirmação. $\mathrm{O}$ comercial do Dia das Mães produzido para este shopping em 2000 mostrava uma mulher muito bonita que olhava para um lado e para o outro enquanto abria 'discretamente' sua blusa; também na cena final é mostrado que trata-se de uma mãe se preparando para amamentar seu bebê. Nesse comercial, a sensualidade se fez presente de forma mais direta.

Face a uma característica básica da televisão - a repetição de suas próprias formas, principalmente o que dá certo (Sarlo, 1997) - é valido se pensar que a estratégia utilizada encontrou repercussão junto ao público. Assim, enfocar a questão da masculinidade e feminilidade parece ser relevante mesmo quando se esperaria que o tema alvo fosse outro (paternidade e maternidade, em função da data comemorativa).

No comercial em análise, a interação entre os homens e do personagem principal com diferentes mulheres possibilita reflexões sobre o padrão de masculinidade veiculado e sobre as relações de gênero. Assim, se o banheiro é o sentido inicial, o/a espectador/a é levado/a a pensar, na segunda cena, pelos olhares mútuos para a linha da cintura, que trata-se da 'hora da verdade' que acontece no encontro de homens em vestiários e banheiros: o confronto do 'tamanho da masculinidade'.

Nesta cena está presente uma série de elementos que coloca H1 
Hennigen, I.; Guareschi, N.M.F. "A paternidade na contemporaneidade: um estudo de mídia sob a perspectiva dos estudos culturais"

como um representante da chamada masculinidade hegemônica ${ }^{8}$ ele é branco, jovem, heterossexual, dominante, auto-centrado. Superior ao outro mais velho, logo, menos viril -, permanece sério enquanto o outro sorri; sendo mais homem, não se deixa envolver por manifestações afetivas sinais com a cabeça, tapinhas nas costas -, só sorri depois de verificar o entorno (a procura de testemunhas?).

Garcia (1998) afirma que a identidade masculina ainda está fortemente alicerçada na sexualidade, outros aspectos experienciais permanecem com valor secundário. Uma leitura possível do comercial pode seguir nessa direção: os cumprimentos que $\mathrm{H} 1$ recebe são em função de sua condição de pai, mas isto parece não ser tão significativo pois ele mostra-se esquivo: seria necessário manter sua 'posição' diante do outro homem?

As próximas cenas mostram a interação de $\mathrm{H} 1$ com três mulheres, cuja posição poderia ser sintetizada da seguinte forma: as primeiras provocam e as últimas compreendem. Na interação com as primeiras, a sedução está presente através do encarar - oferecer o lenço, sorrir - arrumar blusa - suspirar aliviado, chupar pirulito - confrontar; essas mulheres são jovens, vestem roupas decotadas de cores fortes. Já as outras usam roupas discretas e até óculos e não questionam, só acolhem a falta de jeito do homem.

Pode-se dizer que estas imagens estão em sintonia com uma visão tradicional de mútua exclusão, que delimita os comportamentos femininos e continua viva no imaginário social: ou a mulher é 'ativa' ou 'passiva'. As reações de $\mathrm{H} 1$ mostram um rechaço discreto em relação às primeiras (olhar sério para o lenço oferecido, suspiro de alívio) e um relaxamento diante das outras. Assim, tanto na interação com o outro homem, quanto com as mulheres, pode-se constatar uma hierarquia: H1 é o alvo das abordagens, a referência das ações e, mesmo diante de um insucesso, não é criticado.

Este último aspecto pode receber uma outra leitura. O oferecimento do lenço pela M1, para o qual o homem olha sério, pode ser interpretado também com uma forma de confrontá-lo com algo sobre o qual não sabe; por outro lado, a M3 - a mais jovem ${ }^{9}$ - explicita sua reprovação através de repetidos movimentos da cabeça. Pensar nesta direção remete, porém, a um sentido também muito corrente: quem sabe mesmo sobre os cuidados de uma criança é a mulher, o homem só (se) atrapalha.

Finalmente, o pai. Ser pai se resume em contemplar sorrindo o/a filho/a nos segundo finais? Não se pode simplificar tanto assim. Bem ou mal, o comercial coloca um pai diante da troca de fraldas de seu/sua filho/ 
Psicologia \& Sociedade; 14 (1): 44-68; jan./jun.2002

a. A busca da participação paterna nos cuidados das crianças foi/é uma das principais reivindicações das mulheres para a construção de uma relação mais igualitária. Será que o confronto - mais uma vez - com esta 'solicitação' não estaria subjetivando os pais?

O refrão de um antigo comercial - "não basta ser pai, tem que participar!" 10 - poderia muito bem ser considerado um eco do discurso feminista. Mesmo que as cenas mostrem uma inabilidade masculina para fazer a troca de fraldas, a interação pai-filho/a acontece a partir desta situação. Cabe relembrar que os pais entrevistados recentemente por diferentes pesquisadores/as (Ramires, 1997, Saraiva, 1998) referiram justamente a busca de uma participação mais ativa na vida de seus/suas filhos/as como caracterizando sua condição de pai. Mesclam-se no comercial uma iniciativa 'não-tradicional' com uma postura de encolher os ombros como quem diz 'isto é muito complicado para mim'.

"Um novo discurso sempre se instaura a partir dos significados criados na pluridiscursividade. Os novos sujeitos, os novos enunciados constroem-se a partir de velhos sujeitos, de velhos enunciados que criam as condições de emergência do novo" (Pinto, 1989, p. 38). A coexistência de sentidos em conflito na publicidade tem sido assinalada por todos/as aqueles/as que se debruçam sobre os produtos midiáticos relativos às posições sociais de homens e mulheres. Os discursos, as representações que aparecem na mídia, estão relacionados ao conhecimento que circulam na sociedade; os novos significados são construídos a partir das transformações culturais, o que demonstra a face produtiva da cultura (Sabat, 1999).

\section{ALGUMAS IDÉIAS A TÍTULO DE FINALIZAÇÃO}

Ao empreender a análise de um comercial não tínhamos a pretensão de buscar tudo o que está sendo enunciado sobre a paternidade atualmente; ao contrário, nosso objetivo era fazer uma primeira leitura de alguns dos significados que têm circulado na mídia sobre o pai. Certos aspectos já foram discutidos no tópico anterior mas, por suscitarem outros encadeamentos e questionamentos, merecem comentários adicionais. Em primeiro lugar, face à visibilidade que a questão do envolvimento do pai nos cuidados das crianças tem adquirido, é oportuno discuti-la um pouco mais.

A apregoada divisão de tarefas domésticas surge no contexto do movimento feminista e é respaldada por teorias como a de Nancy Chodorow $^{11}$, que encontra nas práticas domésticas não só a explicação para 
Hennigen, I.; Guareschi, N.M.F. "A paternidade na contemporaneidade: um estudo de mídia sob a perspectiva dos estudos culturais"

as diferenças de gênero, mas também a possibilidade do estabelecimento de um novo modelo de relação, baseado na cooperação e complementação entre parceiros, a medida que homens e mulheres compartilharem igualmente cuidados e responsabilidades em relação aos/às filhos/as.

Desde então, parece que o cuidado das crianças se transformou numa espécie de divisor de águas que distingue os pais. O pai 'de verdade' está disponível, participa. A partir dessas considerações é muito fácil se estabelecer uma nova dicotomia - hierarquizada, restritiva e artificial: pai tradicional x novo pai (e, adicionalmente, ligar o novo pai a um hipotético novo homem).

Pensamos que, ao contrário de sustentar novas polaridades, devemos considerar as construções identitárias contemporâneas como marcadas pela composição, flexibilidade, mutabilidade e, sim, pelo que pode afigurar-se como contraditório a primeira vista. Assim, para buscar uma compreensão que contemple a diversidade, é fundamental questionar as formas, significados e abrangência desta participação.

Como propõe Oliveira (1998), talvez uma postura mais igualitária em relação à parceira - incluindo aí a divisão das tarefas domésticas e dos cuidados das crianças - seja possível a apenas uma pequena parcela de homens, cujo status não colocaria em risco sua masculinidade e posição de domínio ao adotar atitudes mais igualitárias. Para o autor, é essencial focalizar a estrutura de poder subjacente às relações de gênero e reconhecer nas dinâmicas de interação cotidianas as condições de manutenção desta mesma estrutura.

A ponderação de Oliveira, ao nosso ver, é muito interessante pois coloca o exercício da paternidade como um aspecto da vivência subjetiva total dos homens, que, necessariamente, vai estar relacionado a muitos outros. Como parte dos estudos de gênero já têm mostrado, não se deve pensar posições identitárias isoladamente.

Assim, ser um pai participativo não pode ser visto simplesmente como um ponto de chegada, esperado e 'redentor'. Quando concebido desta forma, pressupõe a existência de uma espécie de 'essência de pai' a ser alcançada por todos. O ser humano é muito mais complexo, as diferente posições que assume respondem a um emaranhado de forças advindas de suas localizações sociais. Consideramos que compreendê-las é bem mais produtivo que traçar metas 'politicamente corretas'.

O homem-pai, como todo ser humano, é interpelado por diferentes discursos - que têm diferentes forças - e acaba, de alguma forma, respondendo a eles e assumindo posições. O comercial possibilitou vislum- 
brar o que poderíamos caracterizar como um destes jogos de força: o comercial prioriza as relações entre (e intra) gêneros quando fala sobre o pai. O que está realçado é a masculinidade.

Retomando a noção de cultura como o espaço em que ocorre a luta pela significação, é importante refletir sobre o(s) lugar(es) que o pai ocupa em nossa sociedade. Quando e como o pai aparece na nossa cultura (e também na pesquisa)? De uma forma genérica, poderíamos dizer que o pai que falha é muito realçado e, num paradoxo aparente, sua potência é ressaltada e requerida.

O pai é necessário e o pai é falho. Que implicações subjetivas/ sociais advém desta constatação (que, deve-se ressaltar, é uma significação que perpassa nossa cultura). Mais uma vez, é preciso desistir de respostas simples e, alargando a perspectiva, buscar compreender a trama discursiva que compõe a figura do pai.

Consideramos que a análise do comercial possibilitou algumas reflexões sobre a paternidade e seus atravessamentos na cultura/mídia e alcançou seu objetivo de iniciar uma outra forma de discutir este tema. $\mathrm{Na}$ 'tradição' da Psicologia, o pai é objeto de estudo nas áreas do desenvolvimento, personalidade ou clínica: nestas, em geral, a relação pai-filhos/as é vista como algo da esfera privada; mesmo quando são feitas referências ao contexto sócio-cultural mais amplo, este é colocado como uma espécie de coadjuvante, uma variável secundária. Já a Psicologia Social Funcionalista argumenta que a forma como o pai se relaciona com os/as filhos/as é uma função do papel social masculino instituído, que lhe cerceia manifestações afetivas e restringe suas relações. Por outro lado, a proposta de estudar a paternidade sob a perspectiva dos Estudos Culturais implica considerála uma prática social, portanto, vinculada aos sentidos sociais e culturais que lhe são atribuídos.

A contemporaneidade, marcada pela perda dos referenciais pessoais e institucionais ou pela inadequação destes para responder às demandas presentes, oferece uma pluralidade de sistemas de significação e cada um precisa construir sua forma de ser no mundo. Neste contexto, para se almejar uma compreensão mais abrangente das posições de pai em nosso tempo, é fundamental buscar os significados que estão circulando, suas contradições, rupturas com antigas significações, relações com discursos de diferentes ordens, enfim, colocar a paternidade como uma questão cultural. 
Hennigen, I.; Guareschi, N.M.F. "A paternidade na contemporaneidade: um estudo de mídia sob a perspectiva dos estudos culturais"

REFERÊNCIAS BIBLIOGRÁFICAS

ARILHA, M.; MEDRADO, B.; RIDENTI, S. Introdução. In ARILHA, M.; RIDENTI, S.; MEDRADO, B. (Orgs.). Homens e masculinidades: outras palavras. São Paulo: ECOS/Ed. 34, 1998, p. 15-28.

COSTA, M. C. Estudos culturais - para além das fronteiras disciplinares. In . (Org.). Estudos culturais em educação: mídia, arquitetura, brinquedo, biologia, literatura, cinema. Porto Alegre: Ed. UFRGS, 2000, p. 13-36

ESCOSTEGUY, A. C. Estudos culturais: uma introdução. In SILVA, T. T. (Org.). O que é, afinal, estudos culturais? 2. ed. Belo Horizonte: Autêntica, 2000, p. 135-166.

FIGUEIREDO, L. C. A maioridade na psicologia. In Universo Psi, v.2, n. 16,1999, p.5.

FISCHER, R. M. B. O estatuto pedagógico da mídia: questões de análise. In Educação e Realidade, Porto Alegre, v. 22, n. 2, 1997, p. 59-77.

FISCHER, R. M. B. Identidade, cultura e mídia: a complexidade de novas questões educacionais na contemporaneidade. In SILVA, L. H. (Org.). Século XXI: qual conhecimento? qual currículo? Petrópolis: Vozes, 1999, 18-32.

FISCHER, R. M. B. Mídia e produção do sujeito: o privado em praça pública. In FONSECA, T. M. G.; FRANCISCO, D. J. (Orgs.). Formas de ser e habitar a contemporaneidade. Porto Alegre, Ed. UFRGS, 2000, p. 109120.

FISCHER, R. M. B. Uma análise foucaultiana da TV: das estratégias de subjetivação da cultura. Porto Alegre: UFRGS, 2001 (texto digitado), $16 \mathrm{p}$.

FRIDMAN, L. C. Vertigens pós-modernas - a subjetividade contemporânea. In Vertigens pós-modernas: configurações institucionais contemporâneas. Rio de Janeiro: Relume/Dumará, 2000, p. 63-89. 
Psicologia \& Sociedade; 14 (1): 44-68; jan./jun.2002

GARCIA, S. M. Conhecer os homens a partir do gênero e para além do gênero. In ARILHA, M.; RIDENTI, S.; MEDRADO, B. (Orgs.). Homens e masculinidades: outras palavras. São Paulo: ECOS/Ed. 34, 1998, 3150.

GUARESCHI, Neuza Maria de Fátima. Políticas de Identidade: uma breve concepção. Educação (PUC/RS), Porto Alegre, v. 39, p. 7-26, 1999.

GUARESCHI, Neuza Maria de Fátima. Políticas de Identidade: novos enfoques e novos desafios para a Psicologia Social. Psicologia e Sociedade, São Paulo, v. 12, p. 110-124, 2000.

HALL, S. A centralidade da cultura: notas sobre as revoluções de nosso tempo. In Educação e Realidade, Porto Alegre, v. 22, n. 2, 1997, p. 15-46.

HALL, S. A identidade cultural na pós-modernidade. Rio de Janeiro: DP\&A, 1998.

JOHNSON, R. O que é, afinal, estudos culturais? In SILVA, T. T. (Org.). $O$ que é, afinal, estudos culturais? 2. ed. Belo Horizonte: Autêntica, 2000, p. 9-131.

KAUFMAN, G. The portrayal of men's family roles in television commercials. In Sex Roles, v. 41, n. 5/6, 1999, p. 439-458.

KONRATH, I. Discurso paterno: similaridades e especificidades. Dissertação de Mestrado não publicada. Porto Alegre: UFRGS/FACED, 1996.

MCROBBIE, A. Pós-marxismo e estudos culturais. In SILVA, T. T. (Org.) Alienígenas na sala de aula.2.ed. Petrópolis, RJ: Vozes, 1998, p. 39-60.

MEDRADO, B. Homens na arena do cuidado infantil: imagens veiculadas pela mídia. In ARILHA, M.; RIDENTI, S.; MEDRADO, B. (Orgs.). Homens e masculinidades: outras palavras. São Paulo: ECOS/Ed. 34, 1998, p. $145-161$.

MEDRADO, B. Textos em cena: a mídia como prática discursiva. In SPINK, M. J. (Org.) Práticas discursiva e produção de sentidos no cotidiano. 
Hennigen, I.; Guareschi, N.M.F. "A paternidade na contemporaneidade: um estudo de mídia sob a perspectiva dos estudos culturais"

São Paulo: Cortez, 1999, p. 243-271.

MOREIRA, J. O. A invenção do psicológico: considerações sobre a dispersão no campo PSI. In Psique, a. 7, n. 10, 1997, p. 8-21.

NELSON, C.; TREICHLER, P. A.; GROSSBERG, L. Estudos culturais: uma introdução. In SILVA, T. T. (Org.) Alienígenas na sala de aula. 2.ed. Petrópolis, RJ: Vozes, 1998, p. 7-38.

OLIVEIRA, P. P. Discursos sobre a masculinidade. In Estudos Feministas ,v. 6, n. 1, 1998, p. 91-112.

PINTO, C. R. J. Com a palavra o senhor Presidente Sarney: ou como entender os meandros da linguagem do poder. São Paulo: Hucitec, 1989.

RAMIRES, V. R. O exercício da paternidade hoje. Rio de Janeiro: Record/ Rosa dos Tempos, 1997.

SABAT, R. Quando a publicidade ensina sobre gênero e sexualidade. In SILVA, L. H. (Org.). Século XXI: qual conhecimento? qual currículo? Petrópolis: Vozes, 1999, p. 244-261.

SARAIVA, E. S. Paternidade e masculinidade: tradição, herança e reinvenção. Dissertação de Mestrado não publicada. Porto Alegre: UFRGS/ FACED, 1998.

SARLO, B. O sonho acordado. In Cenas da vida pós-moderna intelectuais, arte e vídeo-cultura na Argentina. Rio de Janeiro: Ed. UFRJ, 1997, p. 53-98.

SARUP, M. Identity and difference. In: Identity, culture and the postmodern world. Athens, Georgia: The University of Georgia Press, 1996, p. 46-66.

SILVEIRA. P. Exercício da paternidade. Porto Alegre: Artes Médicas, 1998.

TRINDADE, Z. A.; ANDRADE, C. A.; SOUZA, J. Q. Papéis parentais e representações da paternidade: a perspectiva do pai. Psico, v. $28, \mathrm{n}^{\circ} 1$, Porto Alegre, 1997, p. 207-222. 
VEIGA-NETO, A. Michel Foucault e os estudos culturais. In COSTA, M. V. (Org.). Estudos culturais em educação: mídia, arquitetura, brinquedo, biologia, literatura, cinema. Porto Alegre: Ed. UFRGS, 2000, p. 3769.

\section{NOTAS}

${ }^{1} \mathrm{O}$ que remete ao debate sobre as lutas pela significação no corpo social, lutas que constituem as chamadas políticas de identidade (ver Guareschi, 1999; 2000).

${ }^{2}$ Este material que está sendo recolhido por uma de nós (Inês Hennigen) para a pesquisa de doutoramento.

${ }^{3}$ Que ele próprio caracteriza como um campo de dispersão de saberes e práticas.

${ }^{4}$ Ao longo deste texto, todos os destaques que aparecem nas citações são dos próprios autores.

${ }^{5}$ Neste sentido, indicamos o livro Psicologia Social nos Estudos Culturais, organizado por Guareschi e Bruschi (2002).

${ }^{6}$ É importante ressaltar, seguindo Veiga-Neto (2000) quando discute a aproximação de diferente campos de conhecimento, que não se trata de um jogo de vale tudo, mas da assimilação crítica e pontual de porções de conhecimento, sem esquecer que eles fazem parte de um todo coerente, de um regime de verdade que lhes confere sentido.

${ }^{7}$ Fischer $(1997,2001)$ acredita que as 'coisas ditas' na televisão nos subjetivam não apenas pelo 'conteúdo' das enunciações, mas por todos os elementos de linguagem - a sintaxe - que caracterizam seus produtos; assim, forma e conteúdo não se dissociam e precisam ser contemplados para uma análise mais completa das produções televisivas.

${ }^{8}$ Conceito utilizado por autores interessados em contemplar a dinâmica de poder inscrita nas relações de gênero; refere-se a uma espécie de matriz (constituída num certo tempo histórico, mas que se apresenta como natural, a-histórica) que determina o que é ser homem, excluindo qualquer variação de comportamento masculino não respaldado pela mesma (Oliveira, 1998). Na verdade, este é um dos modos de ser homem e, na vida cotidiana, poucos homens ocupam tal posição e, mesmo assim, não de forma permanente.

${ }^{9}$ Numa sociedade que faz a apologia da juventude, seria esta condição que lhe outorgaria o direito de ser explícita e incisiva?

${ }^{10}$ Como diz Sarlo (1997), a velocidade da TV é superior à nossa capacidade de reter seus conteúdos, o que fica são alguns enunciados dos discursos.

${ }^{11}$ Discutida, por exemplo, em Oliveira (1998) e Ramires (1997). 
Hennigen, I.; Guareschi, N.M.F. "A paternidade na contemporaneidade: um estudo de mídia sob a perspectiva dos estudos culturais"

Inês Hennigen professora da Faculdade de Psicologia da UCS e doutoranda do Programa de Pós-Graduação em Psicologia da PUCRS. O endereço eletrônico da autora é: ihennigen@cpovo.net

Neuza Maria de Fátima Guareschi é professora do Programa de Pós-Graduação em Psicologia da PUCRS e Coordenadora do

Grupo de Pesquisa Estudos Culturais Identidades/Diferenças e

Teorias Contemporâneas. O endereço eletrônico da autora é: nmguares@puc.rs.br <mailto:nmguares@puc.rs.br>

Inês Hennigem e Neusa Guareschi

A paternidade na contemporaneidade: um estudo de mídia sob a perspectiva dos Estudos Culturais.

Recebido dia: 4/6/2002

$1^{\text {a }}$ revisão: $2 / 8 / 2002$

Aceite final: $7 / 8 / 2002$ 